\title{
O CARÁTER GLOBAL DA QUESTÃO AMBIENTAL
}

\author{
Leandro Carvalho Sanson ${ }^{1}$
}

\section{Resumo}

Em um mundo onde as fronteiras se tornaram mais flexíveis, e a velocidade de informações aumenta exponencialmente, novas questões e novos atores assumem protagonismo no cenário internacional. Nesse contexto, os Estados passaram a responder a novos desafios cujos impactos não podem mais ser deixados para segundo plano, tanto no âmbito local quanto no global, como, por exemplo, a degradação ambiental. Neste sentido, buscou-se no presente estudo analisar estes processos de transformações e impactos nas relações sociais e políticas no ambiente do mundo globalizado, considerando aspectos referentes ao papel do Estado e sua relação com a sociedade civil, partindo de elementos como democracia e meio ambiente, bem como, a constituição e dinâmica de uma esfera pública da questão ambiental.

Palavras-chave: Esfera Pública. Meio Ambiente. Globalização. Teoria Social.

\section{Abstract}

In a world where borders have become more flexible, and

1 Mestre em Ciências Sociais pela UFSM / Isociais@yahoo.com.br 
speed of information increases exponentially, new issues and new actors assume leadership in the international arena. In this context, the states began to respond to new challenges whose impact can no longer be left to the background, both locally and globally, for example, environmental degradation. In this sense, we sought in this study to analyze these processes and impacts of changes in social and political environment in the globalized world, considering aspects related to the role of the state and its relationship with civil society, from elements such as democracy and the environment as well as the formation and dynamics of a public sphere of environmental issues.

Keywords: Public Sphere. Environment. Globalization. Social Theory.

\section{INTRODUÇÃO}

A controvérsia encontrada no meio acadêmico acerca das mudanças ocorridas nas ultimas décadas e seus diversos efeitos nas mais variadas relações sociais tais como economia, política, produção e meio ambiente, têm ganho destaque em todo o globo. A relação do ser humano com o ambiente biofísico em que vive tem gerado, principalmente após a década de 60, uma série de produções científicas na teoria social contemporânea, especialmente sobre o estudo da origem e efeitos do processo de degradação do meio ambiente e sua relação com as instituições modernas.

O processo de análise da questão ambiental pela Teoria Social gerou inicialmente grandes controvérsias no meio acadêmico, com um conseqüente lento caminho da abordagem analítica da questão 
InterAção | 213

ambiental pela sociologia.

A incorporação da problemática ambiental na Teoria Social contemporânea acompanhou o fluxo de mudanças ocorrida na sociedade moderna que ocasionou o surgimento de uma nova dinâmica de atuação social, principalmente no que diz respeito à relação Estado, iniciativa privada e sociedade civil, que gerou uma nova racionalidade de ação desses atores. Neste contexto, o Estado passou a ocupar um papel estratégico dentro da Esfera Pública ambiental, pois passou a atuar não só como ator desta esfera, mas também como principal receptor das demandas encaminhadas por ela, na qual exigem do mesmo respostas na forma de uma ação política (de acordo com os interesses dos atores).

O surgimento de um campo sociológico específico sobre a questão ambiental (sociologia ambiental) veio contribuir consideravelmente para o entendimento desta interação entre homem e o ambiente natural em que vive, inserido dentro desta nova dinâmica social.

\section{Teoria Social e a Degradação ambiental}

A questão ambiental, nas últimas décadas do século XX, alcançou o status de problema global e tem mobilizado não apenas os movimentos da sociedade civil organizada e os meios de comunicação, mas também os governos de todas as regiões do globo terrestre. No entanto, apesar da forte organização de práticas e movimentos visando à proteção ambiental, por parte de ONGs e organizações científicas ligadas à perspectiva ambientalista, existe uma divergência no meio científico sobre o efetivo resultado dessa mobilização social 
para solução dos problemas ambientais.

Frederick Buttel (2000) argumenta que a ampla disseminação da preocupação dos setores da sociedade civil e governos com os problemas ambientais, mesmo com a intensa agenda em fóruns internacionais, não geraram um consenso em torno de soluções, ao contrário, à medida que se ampliou o debate em relação à temática, aguçaram os conflitos, e as soluções tornaram-se mais problemáticas do que se poderia imaginar trinta anos atrás.

O Dia da Terra² representa de alguma forma, o início do movimento ambientalista moderno e inaugurou a Década Ambiental nos anos de 1970, onde os sociólogos não encontraram nenhum corpo teórico anteriormente constituído, ou pesquisa, para orientá-los em direção a uma compreensão no relacionamento entre sociedade e meio ambiente (HANNIGAN, 2009). Nesse sentido, as atuais formas de degradação do meio ambiente representam um dos mais, se não o mais, complexo dilema da modernidade. Assim, a emergência desses dilemas passaram a exigir da Teoria Social contemporânea sua inserção analítica a respeito da problemática, buscando meios de contribuir para a explicação dos elementos que compõem esse processo de degradação do ambiente (GOLDBLATT, 1996).

Afastando-se do entendimento do senso comum, a evolução

2 Segundo Hannigan (2009, p.15), o dia da Terra iniciou-se como uma proposta modesta por educação nacional sobre o meio ambiente e cresceu para um evento multifacetado com milhares de participantes. 0 que mais distinguiu o Dia da Terra, entretanto, foi a declaração simbólica de ser o Dia do novo ambientalismo, uma interpretação que foi amplamente aceita pela mídia de massa americana, permitindo, dessa forma, o imediato reconhecimento da causa ambiental por toda parte. 
dos estudos acadêmicos demonstra claramente que inexiste uma explicação simples sobre a origem e os efeitos da degradação ambiental, tornando-se um grande desafio para a Teoria Social contemporânea devido à complexidade que a temática exige. Algumas formulações a respeito têm sido constantemente debatidas no meio científico (ora afirmadas e ora refutadas). Nesse sentido, uma das explicações mais influentes dentro da Sociologia Ambiental para a degradação do ambiente natural é a da relação existente entre o capitalismo, o Estado e o meio ambiente (explicação da economia política) ${ }^{3}$.

Segundo Alan Schnaiberg (1980) apud Hannigan (2009), a economia política dos problemas ambientais e políticas públicas organizadas dentro de uma estrutura da sociedade moderna industrial, gera uma cadeia de produção que se refere à necessidade "inerente de um sistema econômico de continuamente produzir lucro ao criar demanda de consumo para novos produtos mesmo quando isto significa expandir o ecossistema ao ponto no qual excede seus limites físicos de crescimento" (HANNIGAN, 2009. p. 40).

Segundo Hannigan (2009),

Schnaiberg descreve a cadeia de produção como um mecanismo complexo que se autorreforça enquanto os políticos respondem ao estrago ambiental criado pelo crescimento econômico de capital intensivo legislando políticas que encorajam expansão maior ainda. Por exemplo, se lida com a redução de recursos não pela redução do consumo

3 Segundo Hannigan (2009), esta explicação pode ser encontrada no livro de Alan Schnaiberg (1980), onde 0 autor descreve a natureza e gênesis de relações contraditórias entre a expansão econômica e a degradação ambiental. 
ou adoção de um estilo de vida mais moderno, mas sim pela abertura de novas áreas de exploração (HANNIGAN, 2009. p. 40).

Percebe-se, nessa análise detectada pelo autor (Schnaiberg), uma tensão dialética existente entre a cadeia de produção e a necessidade do exercício da proteção ambiental, que, em caráter institucional é obrigatoriedade dos Estados, entre os diversos entes sociais, e, como ela está em voga nas pautas políticas dos governos de todo o globo, o Estado tem se deparado com um grande dilema ${ }^{4}$, pois deve equilibrar gradualmente o seu duplo papel, de facilitador do crescimento econômico e acumulação de capital, bem como, também de protetor e regulador ambiental (HANNIGAN, 2009).

Correntes marxistas, enquadradas dentro da explicação econômica da degradação ambiental, são mais radicais na crítica à dinâmica do desenvolvimento capitalista como propulsor do aumento da destruição ambiental. "David Harvey (1974), o geógrafo marxista, acusa os capitalistas de criar deliberadamente escassez de recursos para que os preços possam ser mantidos altos” (HANNIGAN, 2009. p. 41).

Essa relação dialética existente na relação entre economia, Estado e meio ambiente tem gerado inúmeras divergências analíticas referentes aos verdadeiros causadores e efeitos da degradação am-

4 Conforme argumentado por Redclif, os Estados encontram-se presos em uma posição contraditória, pois se encontram imbuídos de serem os promotores do desenvolvimento econômico e reguladores ambientais, devendo os governos estarem engajados em um processo de gestão ambiental, no qual eles buscam legislar um limitado grau de proteção suficiente para evitar a crítica, mas não 0 suficiente para evitar 0 avanço descontrolado do crescimento econômico (Hannigan, 2009). 
biental pelas relações econômicas e produção. Nesse sentido, a própria explicação da cadeia de produção, conforme entendido por Hannigan (2009), teve a vantagem de localizar a presença de problemas ambientais nas desigualdades dos sistemas políticos e economicamente produzidos pelos humanos, ao invés do abstrato conflito de funções preferido pelos ecologistas humanos.

Anthony Giddens, em sua obra "As Conseqüências da Modernidade (1991)", associou as mudanças ambientais a dois eixos institucionais da modernidade: industrialismo e capitalismo. Ele considera a modernidade multidimensional no âmbito das instituições, e cada um dos elementos especificados por essas várias tradições representam algum papel (Giddens, 1991. p. 21).

Giddens atribuiu ao industrialismo a imputação das causas dos danos ambientais, sendo que, em seu entendimento, a industrialização libertou o crescimento urbano capitalista da economia orgânica avançada dos seus limites ecológicos. Dessa forma, é a dinâmica institucional da economia capitalista que criou as conseqüências da degradação ambiental do industrialismo dentro dos espaços urbanos, ocasionando o aumento de problemas ambientais antigos e o surgimento de novos. Para o autor, a combinação do capitalismo e do industrialismo tornou os problemas ecológicos mais intensos (GOLDBLATT, 1996) $)^{5}$.

5 David Goldblatt (1996), ao analisar a obra de Giddens, critica as explicações causais da degradação ambiental apontada pelo autor, pois a considera frágil e ausente de uma abordagem analítica mais minuciosa. Para 0 autor, o papel das forças políticas e culturais na degradação ambiental são fundamentais para 0 entendimento real de suas causas e efeitos e não foram alvo da abordagem analítica de Giddens. 
No entanto, nenhum desses eixos institucionais (industrialismo e capitalismo) pode ser visto como envolvido unilateralmente nas mudanças ambientais no contexto da modernidade. $\mathrm{Na}$ verdade, ambos fariam parte de um processo geral de interação que teria no urbanismo o seu principal mediador.

Para o sociólogo Ulrich Beck (1992), o que se distingue verdadeiramente sua obra de todos os teóricos sociais contemporâneos, é o fato de o potencial catastrófico da degradação do ambiente, no nível global, ocupar a cena principal.

$\mathrm{O}$ autor afirma que a modernidade descrita nas obras dos teóricos sociais clássicos está sendo transformada num tipo de sociedade fundamentalmente diferente, ou seja, uma sociedade de risco. Essa transformação é, em parte, movida pela emergência de níveis profundos e historicamente incompatíveis com perigos e riscos para o ambiente que atingem uma dimensão e forma tais que os modelos convencionais da sociedade moderna não conseguem apreender as suas origens e conseqüências (BECK, 1992).

O uso do conceito de "sociedade de risco" por Beck (1992) refere-se justamente a essa fase de radicalização dos princípios da modernidade, pois, segundo ele, o progresso gerado pelo desenvolvimento científico e tecnológico torna-se uma fonte potencial de riscos no sentido da possibilidade de autodestruição da sociedade industrial. Os riscos daí resultantes são, em geral, de alta gravidade, ao mesmo tempo em que possuem uma magnitude global, pois tendem a afetar todo o planeta, os riscos são globais.

Tanto para Beck quanto para Giddens, as sociedades altamente industrializadas, próprias do início da modernidade, enfren- 
tam riscos ambientais e tecnológicos que não são meros efeitos colaterais do progresso, mas centrais e constitutivos dessas sociedades, ameaçando todas as formas de vidas no planeta e, por isso, estruturalmente diferentes no que diz respeito as suas fontes e abrangência" (GUIVANT, 1998, p.19).

Os argumentos de Beck relativamente à transformação da modernidade clássica numa sociedade de risco são rigorosamente confrontados com o modelo de Giddens de modernidade tardia radicalizada, no qual os movimentos sociais ambientalistas reagem a riscos e perigos para o ambiente recentemente observados. Beck investiga também os meios pelos quais as relações do poder político e cultural contemporâneo servem para ocultar as origens da degradação do ambiente e proteger os perpetradores dessa degradação. Finalmente, Beck, defende que a democracia e a democratização tanto do processo político convencional como dos centros de decisões econômicas, previamente despolitizados, constitui elemento essencial de uma política de ambiente sustentada.

Nesse sentido, Beck e Giddens conduzem o tema dos riscos para o centro da teoria social contemporânea, ou seja, tais autores (principalmente Beck) propõem não apenas construir um novo conceito dentro da teoria social, mas uma teoria da sociedade global de risco, que estabeleça um novo paradigma teórico dentro da sociologia.

Sendo assim, podemos perceber que o processo de constituição de um campo sociológico que trate da problemática ambiental, bem como a complexidade desse processo, no remete ao entendimento de que a Sociologia Ambiental não trata meramente das dimensões sociais do meio ambiente, mas sim, e isto pode ser afirmado sem 
contradição com a pluralidade de correntes existentes, remete à análise de todo o processo de incorporação do meio ambiente dentro da discussão sociológica.

\section{Esfera Pública Ambiental}

As rápidas mudanças sociais, acarretadas principalmente pelos processos de Globalização, e a ocorrência de graves catástrofes naturais dos últimos anos, com a crescente degradação ambiental, diretamente percebidas pelas mudanças climáticas por todo o globo, vêm sendo interpretadas por muitos como as conseqüências mais evidentes da ação do homem sobre o meio em que vive, demonstrando assim a necessidade de observância da temática nas pautas política e social dos países do globo.

O caráter transnacional das questões ambientais significa também que nenhum país está imune às suas conseqüências. $\mathrm{O}$ paradigma atual do desenvolvimento sustentável traz à tona a necessidade de mudanças em muitas esferas de atuação do Estado e da sociedade. Assim, é justamente nesse cenário global de insegurança e incertezas que acordos internacionais são negociados.

A notória discussão em relação às questões ambientais, conforme já argumentado, tem sido pauta de discussão dos mais diversos atores políticos sociais (ONGs, Movimentos Sociais, Seguimento Artístico, Meio Científico, Iniciativa Privada, Poder Público), gerando uma intensa agenda de debate sobre a questão e a busca de soluções para os iminentes riscos ambientais. Nesse sentido, é possível identificar um novo espaço público de discussão que resulte em formas 
de ação política nesse contexto contemporâneo. É justamente nessa fronteira entre as esferas pública e privada, compreendida não como demarcação de campos antagônicos, mas como faixa de permanente negociação $0^{6}$, que reside a nossa questão.

A questão ambiental, devido principalmente ao envolvimento de uma grande multiplicidade de atores sociais, pode ser caracterizada como uma demanda social de grande complexidade, sendo que a preservação ambiental não envolve aspectos apenas naturais, mas sim culturais, econômicos, políticos, morais, ou seja, de caráter subjetivo e pertencentes ao mundo das relações sociais e humanas.

Assim, é importante entender que a problemática ambiental, inserida na esfera pública contemporânea, é composta por uma série de processos em busca de legitimação enquanto problema global.

Nesse sentido, é importante verificar, dentro desse processo, o papel da mídia como propulsora, ou não, da questão ambiental. Segundo Hannigan (2009), "sem a cobertura da mídia, as possibilidades que um problema prévio possa entrar numa arena do discurso público ou se tornar parte do processo político, são bastante reduzidas" (p.121). De uma forma estratégica, para os problemas ambientais passarem da condição de questão para uma política pública, o papel da mídia é fundamental, no entanto, deve-se ter cautela quanto à teia de significados que ela pode produzir na construção de realidades aparentes ${ }^{7}$.

6 Importante entender aqui a palavra "negociação" como disputa de interesse dos atores envolvidos neste processo, podendo esses interesses serem positivos e/ou negativos à preservação ambiental.

7 Hannigan também destaca que a mídia, ao mesmo tempo em que possui um papel estratégico como difusora dos problemas ambientais e de dar respaldo a estas ques- 
A ciência também ocupa um importante espaço dentro desse processo de legitimação dos problemas ambientais. "É realmente raro encontrar um problema ambiental que não tenha suas origens num corpo de pesquisa científicas" (Hannigan, 2009. p. 141). A estrutura de apoio científico e seu respaldo sobre determinados problemas ambientais, sustentam, acima de outros problemas sociais, as mais dependentes de bases morais. $\mathrm{O}$ avanço dos estudos científicos com a adoção de novas técnicas tem sido fundamental para a descoberta de novos problemas ambientais, que antes era impossível de se descobrir, tornando assim também a ciência um importante colaborador para o processo de formulação de políticas públicas ambientais (HANNIGAN, 2009). Ressalta-se que o próprio debate público em relação aos problemas ambientais, direta ou indiretamente, usa os argumentos científicos para suas formulações, tanto positiva (quando usam como legitimadores de formulações), como negativamente (quando questionados).

Entende-se, assim que, tanto a mídia como a ciência (dentre outros) são agentes importantes dentro deste processo da legitimação e fomento da arena pública sobre a questão ambiental. Nesse contexto, podemos perceber que a entrada da natureza ou meio ambiente no campo da política pode ser vista como uma ampliação da esfera

tões, também é conflitante e complexa, pois, dependendo dos limites organizacionais e rotinas de comunicação dos meios de comunicação, ela pode ter um papel de "construção" de uma realidade aparente sobre a problemática.

8 "A chuva ácida, a perda da biodiversidade, 0 aquecimento global, a redução da camada de ozônio, a desertificação, o dióxido de carbono, são todos exemplos de problemas que começaram com uma série de observações científicas" (HANNIGAN, 2009, p. 141). 
pública, na medida em que os destinos da vida, como preocupação social, conquistam um espaço crescente como objeto de discussão política na sociedade. Da mesma forma, devido principalmente a aspectos político/econômicos, é perceptível uma tensão entre ampliação e/ ou redução dessa esfera pública, evidenciando questões sobre as possibilidades emancipatórias ou desagregadoras de uma fazer político orientado por um ideário ambiental.

É importante ter o entendimento de que a esfera pública ambiental resulta da interlocução entre diversos segmentos da sociedade preocupados com a problemática ambiental. Nesse contexto, a esfera pública constitui a arena viva e dinâmica na qual se envolvem os diversos grupos de interesses em um permanente processo de construção, desconstrução e reconstrução discursiva e simbólica sobre a questão.

Dessa forma, a ação política envolvendo os diversos atores sociais (políticos, empresas e sociedade civil), deve envolver-se nessa nova dinâmica de ação na resolução dos problemas ambientais. Devido ao fato da problemática ambiental não se tratar de um fato isolado, mas sim originário da ação direta do homem na vida social moderna (ex. tecnológicos, culturais, econômico), o Estado deve ser ativo na constituição de mecanismos na busca da resolução dos problemas ambientais, propiciando novas formas de abordar o meio ambiente como tema político, conectando-o a outras questões e proporcionando as condições necessárias para a participação da sociedade civil nesse processo.

Perceber-se que a dinâmica dessa esfera pública ambiental possui uma certa racionalidade de ação, na qual grupos disputam (negociam) dentro de uma arena pública seus interesses (políticos, econômi- 
cos, ecológicos, etc.). O que se deve observar é que, dentre esses atores sociais, o Estado possui um papel chave na manutenção dessa esfera pública, podendo o mesmo ser um cerceador ou fomentador de políticas públicas que venham ao de encontro de certos grupos de interesse.

Nesse sentido, verificando a complexidade de atores envolvidos nesse processo e sendo a questão ambiental um problema global, mas que, acima de tudo, afeta o local, deve-se observar como os atores sociais locais estão atuando em relação a essa problemática.

Em um mundo onde as fronteiras se tornaram mais flexíveis, e a velocidade de informações aumenta exponencialmente, novas questões e novos atores assumem protagonismo no cenário internacional. Essa realidade global desafia ao questionamento antigos conceitos, que voltam à tona, tais como soberania, cidadania, autonomia, poder.

Nesse contexto, conforme mencionado, os Estados passaram a responder a novos desafios cujos impactos não podem mais ser deixados para segundo plano, tanto no âmbito local como no global, como, por exemplo, a degradação ambiental.

A sociedade, nas últimas cinco décadas, passou por mudanças significativas. Processos como a globalização e a expansão da reflexividade social ${ }^{9}$ alteraram o contexto da vida política, levando ao questionamento os paradigmas políticos até então existentes (GIDDENS, 1996).

Tendo em vista a complexidade da nova ordem mundial, cabe

9 Para Giddens, a sociedade moderna, devido a sua complexidade, exige dos indivíduos uma reflexividade social, onde os indivíduos devem se acostumar a filtrar todos os tipos de informações relevantes para as situações de suas vidas e atuar rotineiramente com base nesse processo de filtragem. 
salientar que a globalização não está comandada por forças inexoráveis e nem marcada exclusivamente por relações e processos de natureza econômica. Está, entre outros fatores, sujeita a uma lógica política, que por sua vez, tem a ver com relações assimétricas de poder, que se estabelecem entre as potências em escala mundial. Configuram-se, assim, as redes transnacionais de conexões, através das quais se articulam alianças estratégicas, envolvendo atores externos e internos (DINIZ, 2000a, cap.1).

Certamente estamos em uma fase de transformações sociais, políticas, econômicas, etc. a qual gera grandes incertezas, necessitando, cada vez mais, de novos componentes para lidar com esse novo ambiente social contemporâneo.

O estudo, cada vez mais frequente, de formas de participação política direta e seus efeitos sobre a economia, revelam que a democracia (sob a ótica liberal - representativa) atualmente enfrenta um paradoxo: há um enfraquecimento do processo político democrático ao mesmo tempo em que aumentam as demandas sobre o Estado. No entanto, tal enfraquecimento não se deve à perda dos valores democráticos, mas ao sentimento de frustração que decorre da incapacidade do sistema político tradicional e seus governos democráticos de enfrentar os problemas da desigualdade social, acarretando numa perda de confiança na própria democracia. Surge assim a necessidade de identificar os efeitos e as formas de participação política, dos diversos atores sociais, e seus processos democráticos (tradicionais ou novos), na busca de soluções desses problemas sociais, como a problemática ambiental.

É na obra de Robert Dahl (1997), que encontramos uma 
concepção mais próxima a uma racionalidade de ação de uma esfera pública a partir de processos democráticos modernos. Para o autor, as democracias existentes são efetivamente pobres aproximações do ideário democrático. Dessa forma, ele sugere que estas sejam chamadas de poliarquias ${ }^{10}$. Nesse sentido, a democratização é um processo de progressiva ampliação da competição e da participação política. Assim, são estabelecidos pelo autor dois eixos analíticos fundamentais para a identificação da democratização nos Estados, ou seja, a competição política e a participação (DAHL, 1997).

Fernando Limongi, no prefácio da obra de Robert Dahl expõe:

A democracia, afirma Dahl, é fruto de um calculo de custos e benefícios feitos por atores políticos em conflito. $\mathrm{O}$ ponto de partida dessa formulação é a premissa de que todo e qualquer grupo político prefere reprimir a tolerar seus adversários (LIMONGI apud DAHL, 1997. p. 21).

Conforme visto, a democracia é, sobretudo, fruto de um cálculo de atores políticos inseridos em uma relação estratégica e sustentados por um equilíbrio de forças. Nessa arena pública de disputa de interesses insere-se também a questão ambiental, pois, conforme já argumentada neste estudo, envolve uma série de grupos de interesses conflitantes (movimento ambientalista, ONGs, iniciativa privada,

10 Para Dahl, não existe de fato um regime plenamente democrático, mas sim regimes que apresentam graus de democratização. Assim, as poliarquias são pensadas como regimes relativamente (mas incompletamente) democratizados, ou, em outros termos, as poliarquias são regimes que foram substancialmente popularizados e liberalizados, isto é, fortemente inclusivos e amplamente abertos à contestação pública. 
políticos, etc.) cabendo ao Estado o papel de ator mediador e responsivo ${ }^{11}$ pela busca do equilíbrio dessas forças em disputa. Mais ainda, percebe-se claramente, dentro do processo democrático, uma racionalidade dos agentes na sua ação, através de um cálculo estratégico de custos e benefícios.

Conforme demonstrado na presente pesquisa, os problemas ambientais são as fontes primordiais de riscos no mundo moderno, $\mathrm{e}$ os impactos ambientais estão intimamente ligados aos processos da sociedade moderna, agindo em diferentes dimensões.

Dessa forma, a ação política, envolvendo os diversos atores sociais (políticos, empresas e sociedade civil), compromete-se nesta nova dinâmica de ação com a resolução dos problemas ambientais. Devido ao fato da problemática ambiental não se tratar de um fato isolado, mas sim originário da ação direta do homem na vida social moderna (ex. tecnológicos, culturais, econômico), o Estado deve ser ativo na constituição de mecanismos na busca da resolução dos problemas ambientais, propiciando novas formas de abordar o meio ambiente como tema político, conectando a outras questões, e proporcionando as condições necessárias para a participação da sociedade civil nesse processo.

\section{CONSIDERAÇÕES FINAIS}

Conforme demonstrado no presente estudo, o novo contexto social, originário dos processos de globalização, exige uma nova es-

11 Que faça parte de um sistema que responda as preferências de seus cidadãos, considerados politicamente iguais, e garantindo oportunidades plenas. 
truturação das relações sociais, nos mais diversos níveis (economia, política, costumes, tradição, etc.), inferindo ao cidadão um novo agir sociológico e político, com uma atuação do Estado diferenciada das que tradicionalmente (concepção ortodoxa) lhe era atribuída, voltada agora mais para a promoção da sociedade em graus de liberdade e oportunidades.

A análise até aqui realizada, possibilitou vislumbrar a constituição e efeitos de um novo ambiente social (entendido por alguns como novo paradigma), proporcionado pelo avanço das rápidas mudanças sociais, que auferiram às relações sociais (na sua completude geral) a necessidade de um novo "agir", com base em uma sociedade de relações complexas dotadas de "incertezas artificiais" e "riscos".

Importante se observar, que o campo ambiental é também portador dos dilemas contemporâneos que afetam a esfera política, particularmente no que diz respeito as escolhas e ações presentes que vão incidir sobre o futuro, como projeto de vida comum.

A política aqui é percebida, como esfera pública, espaço por excelência da ação humana como convivência com os outros humanos e partilha nas decisões sobre os destinos dos bens comuns.

Nesse sentido, é sabido que os bens ambientais vêm se instituindo na esfera pública com o status de Bem comum de grande relevância para a sociedade. Como tal, a questão ambiental tem alcançado um lugar destacado nos embates sobre a construção social do futuro da comunidade humana, vinculando as atuais e as novas gerações numa esfera de negociação de projetos de sociedade e modos de engajamento político.

Ao se ligar as teorias sociais contemporâneas ao objeto do 
presente estudo remete-se a idéia da constituição de uma nova esfera pública ambiental, englobando a diversidade dos participantes no ambiente do diálogo, e na disputa de interesses.

Neste contexto, a constante preocupação social e política das questões vinculadas ao meio ambiente, principalmente referente à imagem de uma contínua deteriorização da vida humana, e sistemas ecológicos, gerou uma grande sensibilização social acerca da temática, que proporcionou o surgimento de idéias e posturas na opinião pública sobre os problemas ambientais.

Neste sentido a exposição pública dos problemas que dizem respeito ao meio ambiente passou a ser abordada por um conjunto de conceitos, valores, problematizações, dimensões e ações construídas em torno da percepção da relação da sociedade com seu ecossistema. Conforme destaca Jollivet, "a questão do meio ambiente é uma interrogação institucionalizada que mobiliza e organiza as representações coletivas" (1994, p. 184), e assim emergindo publicamente.

Dessa forma, observamos que ao publicizar um tema considerado socialmente relevante, através de discussões ou ações sobre o agir humano para com o meio ambiente, gera ideologias e conceitos, acabando também por exercer uma pressão social sobre as decisões políticas. Esse processo de inter-relação social entre Estado e Sociedade Civil sobre os problemas ambientais se da em um espaço intermediário considerado público (Esfera Pública), onde envolve a participação de diversos interesses.

A Esfera Pública é compreendida em razão dos discursos e ações dos atores que fazem dela um contexto para a manifestação de diversos interesses, problematizações e opiniões em torno a assun- 
tos considerados relevantes (COSTA, 1995). Assim, a esfera pública compreende um processo dinâmico de relações sociais, fundamentadas em argumentos, discursos e ações, onde se limitam valores éticos e ideologias, na busca de propostas de ações. É o espaço que se da a emergência de temas que saem do privado para o público, com o envolvimento de diversos segmentos sociais.

Conforme já argumentado, a questão ambiental, juntamente com outros problemas sociais, tornou-se uma temática pública, com o reconhecimento de diversos atores (individuais e coletivos), formando uma esfera pública com a devida exposição de interesses, conflitos, alianças, etc. Esta arena pública (conforme retratada por Dahl, 1997), é um espaço de interação democrática que envolve diversos atores que por sua vez aplicam, conforme seus interesses (calculo de custos e benefícios) uma estratégia de ação, devendo o Estado assumir um papel de mediador deste processo.

Portanto, na esfera pública ambiental estão expostos interesses e conflitos, garantindo as condições para o acesso de grupos de interesses, e a possível omissão de outros, mas com a inevitável repercussão na esfera política. Assim, as políticas públicas ambientais adquirem um caráter estatal ao inserirem-se nas relações entre Estado e Sociedade, sendo que as ações (ou omissões) sobre certas demandas vinculam ambos na construção deste processo.

\section{REFERÊNCIAS}

BECK, U. Risk Society. Towards a New Modernity. London: Sage Publications, 1992. 
BUTTEL, F. Sociologia ambiental, qualidade ambiental e qualidade de vida: algumas observações teóricas. In: HERCULANO, S.; PORTO, M.; FREITAS, C. (Org.). Qualidade de vida e riscos ambientais. Niterói: EDUFF, 2000.

COSTA, S. A Democracia e a Dinâmica da Esfera Pública. Revista Lua Nova, n. 36. São Paulo: Ed. TEC ART LTDA, 1995.

DAHL, R. Poliarquia: Participação e Oposição / Robert Dahl; prefácio Fernando Limongi. São Paulo: Editora da Universidade de São Paulo, 1997.

DINIZ, E. Globalização, reformas econômicas e elites empresariais. Rio de Janeiro, FGV, 2000 - a.

GIDDENS, A. As conseqüências da modernidade. São Paulo: Universidade Estadual Paulista, 1991.

.Para além da esquerda e da direita. $\mathrm{O}$ futuro da política radical. Trad. de Alvaro Hattnher. São Paulo: Ed. UNESP, 1996.

(org). O debate Global sobre a Terceira Via. São Paulo: Editora UNESP, 2007.

GOLDBLATT, D. Teoria Social e Meio Ambiente. Lisboa: Instituto Piaget, 1996.

GUIVANT,Julia.A trajetória das análises de risco: da periferia ao centro da teoria social. Revista de Informações Bibliográficas - ANPOCS, n. 46, p. 3 - 38, 1998.

HANNIGAN, J. Sociologia Ambiental. Petrópolis, RJ: Editora Vozes Ltda, 2009. 
LUCHMANN, L.H.H. A Democracia Deliberativa: Sociedade Civil, Esfera Pública e Institucionalidade. Cadernos de Pesquisa, n. 33 PPGSP/UFSC - ISSN - 1677-7166. Novembro de 2002.

RAICHELIS, R. Assistência social e esfera pública: os conselhos no exercício do controle social. Serviço Social \& Sociedade, São Paulo, Cortez, n. 56, p. 77-96, 1998.

SEN, Amartya. Desenvolvimento como liberdade. São Paulo: Companhia das Letras, 2000. 